ISSN: $1980-055 X$

\title{
SISTEMAS ATMOSFÉRICOS GERADORES DE EVENTOS EXTREMOS DE PRECIPITAÇÃO EM OUTUBRO DE 2006 NO DISTRITO FEDERAL: UMA ANÁLISE GEOGRÁFICA DOS DESASTRES
}

\author{
Ercília Torres Steinke ${ }^{1}$, Mariana de Souza Rezende ${ }^{2}$ e Luiz Cavalcanti ${ }^{3}$
}

\begin{abstract}
RESUMO
Nos últimos anos, em vários países, os desastres naturais de origem climática têm ocupado a atenção de pesquisadores, organizações governamentais e não-governamentais e os meios de comunicação. No Distrito Federal não é diferente. A cidade de Brasília, mesmo com status de capital do Brasil, juntamente com as demais Regiões Administrativas que compõem o Distrito Federal vem apresentando, já há alguns anos, inúmeros casos de desastres naturais de origem climática que têm afetado diretamente a população. No mês de outubro de 2006 foram totalizados na estação do INMET 526,4 mm de chuva, o que corresponde a $205 \%$ a mais que a Normal Climatológica do mês. Esse trabalho teve como objetivo principal analisar, sob uma perspectiva geográfica, os sistemas atmosféricos geradores de eventos extremos de precipitação que atuaram no mês de outubro de 2006 e os impactos pluviais decorrentes desses eventos no Distrito Federal. Observou-se que os temporais que causaram inúmeros desastres na região foram provocados pelo encontro da umidade proveniente da Amazônia com frentes frias do Sudeste que promoveram a formação de inúmeras áreas de instabilidade. Contudo, não se pode delegar somente à chuva a origem dos desastres registrados durante o mês. A intensa urbanização também contribui para os impactos pluviais observados.
\end{abstract}

Palavras-chave: Impactos pluviais, urbanização, Distrito Federal

\section{ATMOSPHERIC SYSTEMS THAT GENERATES RAINFALL EXTREME EVENTES IN OCTUBER/2006 AT DISTRITO FEDERAL: AN GEOGRAPHICAS ANALISYS OF DISASTERS}

\begin{abstract}
In the last few years, climate natural disasters have attracted the attention of

1 Geógrafa, professora Doutora do Departamento de Geografia da Universidade de Brasília (UnB), coordenadora do Laboratório de Climatologia Geográfica - LCGea, Campus universitário Darcy Ribeiro, ICC Norte, subsolo, módulo 23, Brasília - DF, Brasil, ercília@unb.br

2 Graduanda do Curso de Geografia da Universidade de Brasília (UnB), bolsista de PIBIC do Laboratório de Climatologia Geográfica - LCGea, Campus universitário Darcy Ribeiro, ICC Norte, subsolo, módulo 23, Brasília - DF, Brasil, naninharezende@hotmail.com

3 Meteorologista, chefe do setor de previsão do tempo do Instituto Nacional de Meteorologia INMET. Eixo Monumental, Via S1, Sudoeste, Brasília, cavalcanti@inmet.gov.br
\end{abstract}


researchers, governmental organs, non-governmental organizations and the media. This is not different in the Brazilian Federal District. In the last few years, Brasília, despite being the capital of Brazil, as well as the other Administrative Regions that compose the Federal District, has had innumerable cases of climate natural disasters which have directly affected the population. In the month of October $2006,526,4 \mathrm{~mm}$ of rain were recorded at the INMET station, which corresponds to an increase of $205 \%$ in the of that month. This study aimed mainly at analyzing the atmospheric systems in the month of October that caused extreme precipitation events and at systematizing the data on pluvial impact in the Federal District. It was observed that the storms which caused innumerable disasters in the region were caused by both the humidity from the Amazon and the cold fronts present in the southeastern and northeastern coasts which formed instability areas. However, one cannot attribute the origin of the disasters recorded during that month to the rain only. Intense urbanization also contributes to the pluvial impact observed.

Key words: Pluvial impacts, urbanization, Federal District

\section{Introdução}

Compreendendo uma área de $5.814 \mathrm{~km}^{2}$ drenada por rios que pertencem a três das mais importantes bacias fluviais da América do Sul (bacia do Paraná, bacia do São Francisco e bacia do Tocantins), abrigando o cerrado como vegetação predominante e apresentando elevados índices de crescimento urbano e populacional, o Distrito Federal se apresenta como uma área cuja necessidade de estudos de climatologia se faz fundamental, até mesmo em função de sua condição de centro político-administrativo do país.

Por esse motivo Monteiro (1969), certo da importância de deixar sua contribuição para o futuro das investigações climatológicas pertinentes à geografia brasileira, já na década de 60, chamou a atenção para a necessidade de estudos sobre as condições climáticas do Planalto Central, incluindo Brasília, uma vez que se trata da Capital do país e de importante pólo ordenador de desenvolvimento. Mais tarde, Zavatini $(1996,2003)$ constatou que a Região Centro-Oeste ainda permanecia carente de estudos de climatologia dinâmica, chamando novamente a atenção para Brasília.

Ainda hoje, a dinâmica climática e suas repercussões dessa importante região são pouco estudadas e muito se tem especulado à respeito do clima do Distrito Federal e de prováveis mudanças ocorridas em função da urbanização desordenada. Assim, considerando-se a carência de estudos de climatologia abrangendo o Distrito Federal e tendo em vista que questões referentes ao clima fazem parte do dia-a-dia da população, justifica-se a adoção dessa área como objeto de estudo.

A chuva, em especial, tem despertado relativo interesse devido aos problemas gerados a partir de eventos intensos, como alagamentos em pontos específicos, quedas de barrancos e de árvores, queda de energia e etc. Todos esses problemas podem ser considerados desastres.

Os desastres naturais constituem-se em preocupação da humanidade 
desde que eram considerados obra dos Deuses. Posteriormente, eventos considerados catastróficos tais como, terremotos, erupções vulcânicas, tsunamis, furacões, tornados, secas, inundações e enchentes foram atrelados aos processos naturais do planeta Terra. Nos últimos anos, os desastres naturais de origem climática têm ocupado a atenção de pesquisadores, organizações governamentais e não-governamentais e os meios de comunicação. E isso vem ocorrendo em função da imensa quantidade de registros dessa natureza. Segundo Alexander (2004), no período compreendido entre 1992 a 2001 ocorreram cerca de 2.730 desastres naturais, matando 535.000 pessoas e afetando a vida de mais de 2.000.000 em todo mundo. Destes, os mais freqüentes foram as enchentes/inundações e as tempestades tropicais.

Embora "desastres naturais" ocorram em todas as partes do mundo, seu impacto recai desproporcionalmente sobre as populações pobres, que vivem em áreas vulneráveis e dispõem de poucos recursos para se precaverem ou se recuperarem das calamidades. Entre 1985 e 1999, 96\% das fatalidades causadas por desastres registraram-se em países em desenvolvimento.

No Distrito Federal não é diferente. A cidade de Brasília, mesmo com status de capital do Brasil, juntamente com as demais Regiões Administrativas $\left(R^{\prime} s\right)$ que compõem o Distrito Federal vem apresentando, já há alguns anos, inúmeros casos de desastres naturais de origem climática que têm afetado diretamente a população, e como já era de se esperar, os habitantes das regiões periféricas do Distrito Federal são os mais atingidos.

Um desastre climático pode ser considerado como conseqüência da combinação entre riscos naturais e atividades humanas. A vulnerabilidade natural de determinadas áreas e a do ser humano leva a inúmeras perdas financeiras, estruturais e de vidas humanas, sendo que a perda resultante depende da capacidade da população de resistir a um evento extremo evento. Portanto, desastres ocorrem quando riscos encontram vulnerabilidade. Assim um risco natural nunca resultará em um desastre em áreas que não apresentem vulnerabilidade, por exemplo, em 1963 ocorreu um evento pluviométrico de grande intensidade (132,8 mm em 24 horas) na cidade de Brasília, mas como nessa época, a cidade ainda era pouco habitada, não houve registros de desastres. Hoje, se o mesmo evento ocorresse, certamente, alguns dos mais de 2.000.0000 de habitantes do Distrito Federal sofreriam com inundações, uma vez que o Distrito Federal vem passando por um processo de ocupação desordenada acompanhada de impermeabilização do solo por meio da substituição da cobertura vegetal por asfalto.

E é justamente o que ocorre durante o período chuvoso. A cada ano que passa a Defesa Civil do Distrito Federal registra mais ocorrências de alagamentos e enchentes em inúmeros pontos da região. Quando ocorrem eventos de chuvas fortes e consecutivos, o caos instala-se na cidade. Foi o que ocorreu no mês de outubro de 2006. Nesse mês foi registrado, na estação do INMET, um total mensal de $526,4 \mathrm{~mm}$, o que corresponde a $205 \%$ a mais que a Normal Climatológica do mês. Este fato causou inúmeros transtornos para a população, principalmente porque, historicamente, o mês de outubro não tem como característica ser muito chuvoso. Nesse contexto, esse trabalho teve como objetivo principal analisar os sistemas atmosféricos que atuaram no mês de outubro gerando eventos extremos de precipitação, sistematizar os dados sobre os impac- 
tos pluviais e indicar, com base nesses dados, as principais áreas de risco de inundação no Distrito Federal.

\section{Área de estudo}

A área de estudo compreende o limite político-administrativo do Distrito Federal do Brasil, já bastante caracterizado na literatura. Porém, uma breve descrição das características climáticas da região se faz necessário, uma vez que estas constituem o foco da presente pesquisa.

Segundo Steinke (2004), associados aos Anticiclones do Atlântico e do Pacífico, à Alta da Bolívia, à Baixa do Chaco, a Zona de Convergência Intertropical (ZCIT) e às altas pressões polares, diversos mecanismos atmosféricos atuam ao longo do ano sobre o Brasil, tais como: as invasões de massas de ar frias e secas, provenientes do sul, em contraste com as massas quentes e úmidas que caracterizam sistemas frontais periódicos. Combinados a esses fatores de grande escala, agem fatores locais e regionais, determinando a caracterização climática de cada região do país.

A região Centro-Oeste é dominada pela massa Tropical Atlântica (mTa) que, devido à ação persistente do Anticiclone Semipermanente do Atlântico Sul, possui atuação relevante durante o ano todo. Durante o verão a massa Equatorial Continental ( $\mathrm{mEc}$ ), atraída pelos sistemas depressionários do interior do continente, como a Baixa do Chaco, tende a avançar do NW, ora para SE, ora para ESE, atingindo a região Centro-Oeste, onde provoca elevação das temperaturas, sendo responsável ainda pelo aumento da umidade e das precipitações.

De acordo com NIMER (1989), associados à essas massas de ar, contribuem para a gênese climática na região Centro-Oeste os seguintes sistemas de circulação descritos abaixo: sistema de correntes perturbadas de oeste - de linhas de instabilidade tropicais (IT); sistema de correntes perturbadas de norte - da zona de convergência intertropical (ZCIT); sistema de correntes perturbadas de sul - do anticiclone polar e frente polar atlântica (FPA).

Os sistemas de circulação atmosférica que atuam no Centro-Oeste, associados à posição geográfica do Distrito Federal, permitem observar na região dois períodos marcantes, um seco e outro úmido. Segundo BARROS (2003), de maneira geral pode-se dizer que o período compreendido entre os meses de maio a setembro (seco) possui as seguintes características: intensa insolação, pouca nebulosidade, forte evaporação, baixos teores de umidade no ar, pluviosidade reduzida e grande amplitude térmica (máximas elevadas e mínimas reduzidas).

O inverso se dá no semestre outubro a abril (úmido): a insolação se reduz, a nebulosidade aumenta, diminui a evaporação, os teores de umidade do ar aumentam, a pluviosidade se intensifica e a amplitude térmica moderadamente reduz-se, pois as máximas mantêm-se e as mínimas elevam-se.

O período úmido corresponde ao final da primavera e ao início do verão. Nesse período, o continente é dominado por intensos conglomerados de nuvens convectivas responsáveis por fortes chuvas. As baixas pressões em superfície se expandem e dominam grande parte do território. Em altitude, a Alta da 
Bolívia se estabelece em sua posição mais característica (BRANDÃO, 1996).

Essa característica determina, no Distrito Federal, menores valores de evaporação e de insolação (devido à presença de nuvens), maiores valores de umidade relativa do ar e redução na amplitude térmica, pois as temperaturas máximas são menos intensas, ao passo que as mínimas são mais elevadas.

As características climáticas da segunda quinzena do mês de março e do mês de abril representam a passagem do período úmido e de menores amplitudes térmicas para o mais seco e de maiores amplitudes térmicas. O mês de março ainda é considerado um mês chuvoso em função da vigência da situação de verão.

Por volta da segunda metade da estação do outono, a circulação atmosférica sofre uma mudança. $\mathrm{O}$ cinturão de altas pressões subtropicais (em superfície) instala-se, dando início ao período seco, que no Distrito Federal compreende os meses de maio a setembro.

NIMER (1989) descreveu a atuação do Sistema de Correntes Perturbadas de Sul na região Centro-Oeste destacando que, no inverno, a invasão do Anticiclone Migratório Polar provoca queda de temperatura com céu limpo e a determinação de características climáticas que implicam em baixos teores de umidade relativa do ar que, por sua vez, associam-se aos baixos valores de chuva, assim compondo um longo período de estiagem.

Os meses de setembro e outubro também são considerados de transição, representando a passagem do período seco para o úmido. Setembro apresenta ventos fortes, os valores de temperatura mais elevados e registra os menores índices de umidade relativa do ar. No interior do continente, os conglomerados convectivos começam a se formar, quando, então, a situação de verão se restabelece, rompendo o bloqueio atmosférico (cinturões de alta pressão subtropicais) e determinando, assim, o início do ano hidrológico para o Distrito Federal.

\section{Material e métodos}

Foram utilizados dados diários de precipitação (últimas 24 horas) e de temperaturas do ar mínima e máxima provenientes da estação Brasília do Instituto Nacional de Meteorologia - INMET, localizada no Setor Sudoeste do Distrito Federal, do período compreendido entre os dias 01 e 31 de outubro de 2006. Utilizou-se, também, cartas sinóticas de superfície das 00:00, 12:00 e 18:00 UTC e imagens do satélite GOES no canal 4 (infravermelho) obtidas nos sítios do Departamento de Hidrologia e Navegação - DNH da Marinha, e do Centro de Previsão e Estudos Climáticos - CPTEC/INPE, respectivamente, para o mesmo período com a finalidade de identificar os sistemas atmosféricos atuantes, analisando a circulação atmosférica regional e a atuação das massas de ar e frentes por meio das imagens de satélite e cartas sinóticas.

A identificação dos problemas originados em decorrência das características do tempo no período estudado e a delimitação das áreas mais atingidas foi realizada por meio da análise diária das ocorrências registradas pelo Corpo de Bombeiros Militar e da Defesa Civil, além de informações oriundas dos jornais de maior circulação no Distrito Federal - Correio Braziliense e Jornal de Brasília - 
sobre os impactos causados pelo excesso de chuva durante o mês de outubro.

\section{Resultados e discussão}

Durante o mês de outubro de 2006, segundo informações do Boletim Climanálise (vol. 21 No 10) os totais de chuva estiveram de normal a acima da média no Distrito Federal sendo que nessa região foi observada uma grande anomalia de precipitação no período. Em Brasília, por exemplo, o total de chuva alcançou, segundo registros do INMET, 526,4 mm, o qual corresponde a $205 \%$ a mais que a Normal Climatológica para o mês. As figuras 1 e 2 representam a chuva acumulada em 24 horas para o mês de outubro e a chuva acumulada mensal versus a Normal Climatológica para o mês de outubro, respectivamente. Observa-se que o mês de outubro de 2006 apresentou uma quantidade de chuva muito acima do esperado.

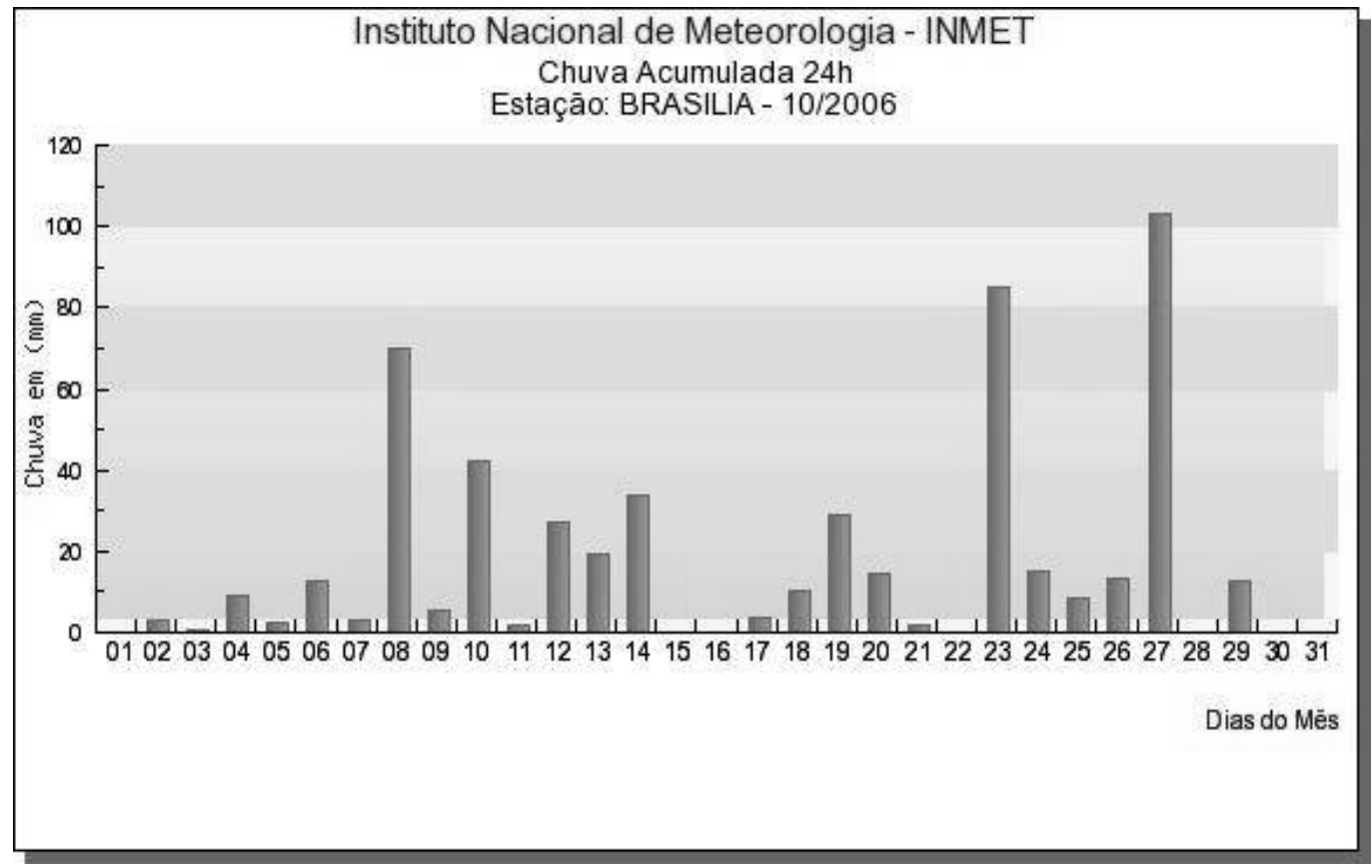

Figura 1. Chuva acumulada em 24h para o mês de outubro de 2006.

Fonte: http://www.inmet.gov.br/html/observacoes

Quatro frentes frias atingiram a região no mês de outubro, dinâmica considerada incomum nessa época, embora as condições atmosféricas já apresentassem características da estação chuvosa. Essas frentes provocaram as anomalias de precipitação quando o escoamento do ar proporcionou condições favoráveis ao desenvolvimento de áreas de instabilidade em grande parte dos dias de outubro. Vale ressaltar que, embora incomum, o fato desse mês de outubro ter apresentado elevados totais de chuva, não configura alteração no parâmetro 
e muito menos mudança climática. Ademais, o mesmo fato ocorreu no ano de 1981 e não foi atrelado à nenhuma anormalidade no clima do Distrito Federal.

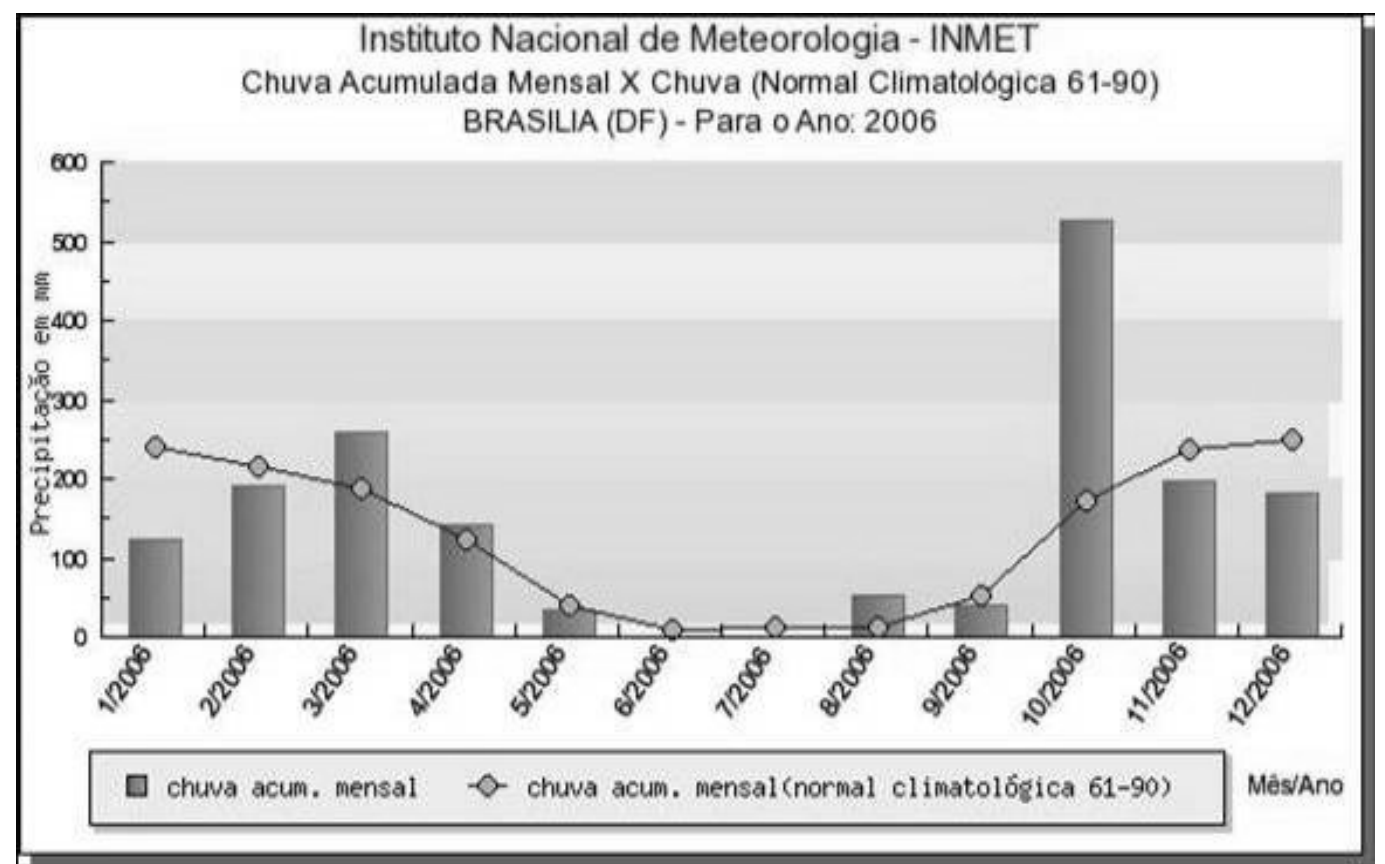

Figura 2. Chuva acumulada mensal x Normal Climatológica para o mês de outubro de 2006.

Fonte: $h t t p: / / w w w . i n m e t . g o v . b r / h t m l / o b s e r v a c o e s$

A atuação dos sistemas frontais e as elevadas temperaturas contribuíram para as chuvas significativas sobre o Estado de Goiás e Distrito Federal. Houve registro de chuvas fortes como a que ocorreu entre os dias 7 e 8 e que totalizaram $69,7 \mathrm{~mm}$ em $24 \mathrm{~h}$. Esse evento teve início aproximadamente às $15 \mathrm{~h}$ do sábado (07/10). Em questão de meia hora o céu da capital federal se escureceu devido à formação de imensas nuvens de tempestade, uma forte chuva foi iniciada e se estendeu até a manhã do dia seguinte. A chuva provocou alagamentos em diversos pontos do Distrito Federal. Samambaia, Vicente Pires, Guará, Paranoá e Taguatinga foram as cidades mais atingidas e onde foram registradas a maioria das ocorrências pela Defesa Civil e pelo Corpo de Bombeiros. As figuras 3 e 4 ilustram a configuração desse evento. A figura 5 representa a repercussão que o evento gerou na imprensa.

As áreas de instabilidade que influenciaram a região Centro-Oeste, nesse mês, contribuíram para um grande aumento na quantidade de chuva. Mesmo estando ainda na primavera, estação de transição entre o período seco e chuvoso na Região Centro-Oeste, já no dia 19 de outubro haviam sido totalizados $272,3 \mathrm{~mm}$ de precipitação na estação Brasília, $57 \%$ a mais do que a Normal Climatológica que é de $172 \mathrm{~mm}$. Por esse motivo, esse mês de outubro já estava sendo considerado o mais chuvoso desde 1981 e provavelmente, superaria o recorde que era de $425,8 \mathrm{~mm}$, o que de fato ocorreu. 


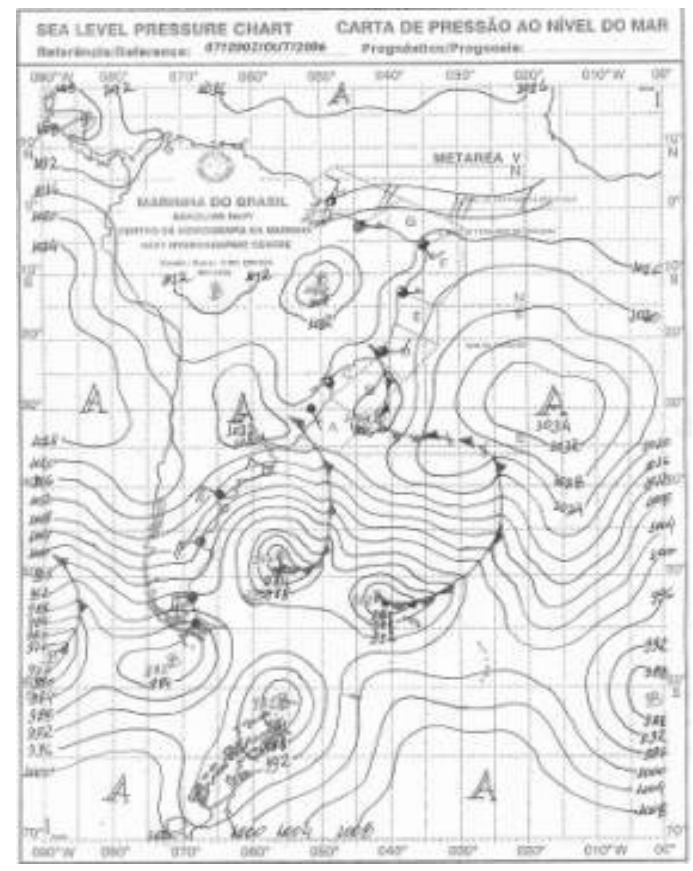

Figura 3. Carta sinótica do dia 07 de outubro às 12:00 UTC.

Fonte:http://www.mar.mil.br/dhn/chm/met eo/prev/cartas/cartas.htm

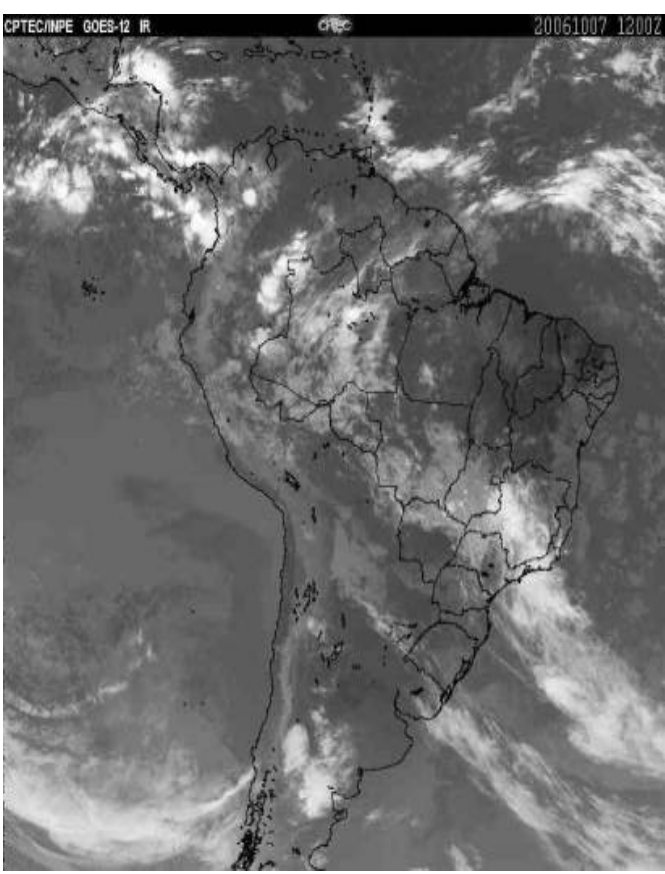

Figura 4. Imagem do satélite GOES 12, canal infra-vermelho do dia 07 de outubro às 12:00 UTC

Fonte: $h t t p: / / s a t e l i t e . c p t e c . i n p e . b r /$

A Zona de Convergência do Atlântico Sul (ZCAS) esteve atuante nesse mês, causando chuvas fortes como o do dia 23 que, devido a áreas de instabilidade forçadas pela sua presença, provocou grandes temporais. Segundo o INMET, esse evento teria sido o maior registrado até então no mês: $84,8 \mathrm{~mm}$, das $9 \mathrm{~h}$ de domingo às $9 \mathrm{~h}$ de segunda-feira. As figuras 6 e 7 ilustram a atuação desse sistema.

Como resultados do temporal do dia 23 foram observados inúmeros alagamentos e enchentes, casas inundadas e famílias desabrigadas. As figuras 8 e 9 representam a repercussão na imprensa e demonstram que o Distrito Federal não está preparado adequadamente para enfrentar eventos extremos de chuva. As ocorrências foram registradas, principalmente, na Vila Fercal, Núcleo Bandeirante, Vicente Pires, Ceilândia, Estrutural, Varjão, Vila Cauhy, Riacho Fundo e diversas outras regiões do Distrito Federal. Tantas foram as ocorrências contabilizadas pelos órgãos de segurança que foi possível elaborar uma primeira aproximação do que vem a ser um mapa de risco de inundações no Distrito Federal (ver figura 10). As áreas indicadas constituem-se em resultado de uma ocupação desordenada, apresentam deficiência de infra-estrutura e muitas delas não possuem saneamento básico. Segunda a Defesa Civil, pelo menos 290 pessoas foram atingidas por enxurradas durante o temporal do dia 23. 


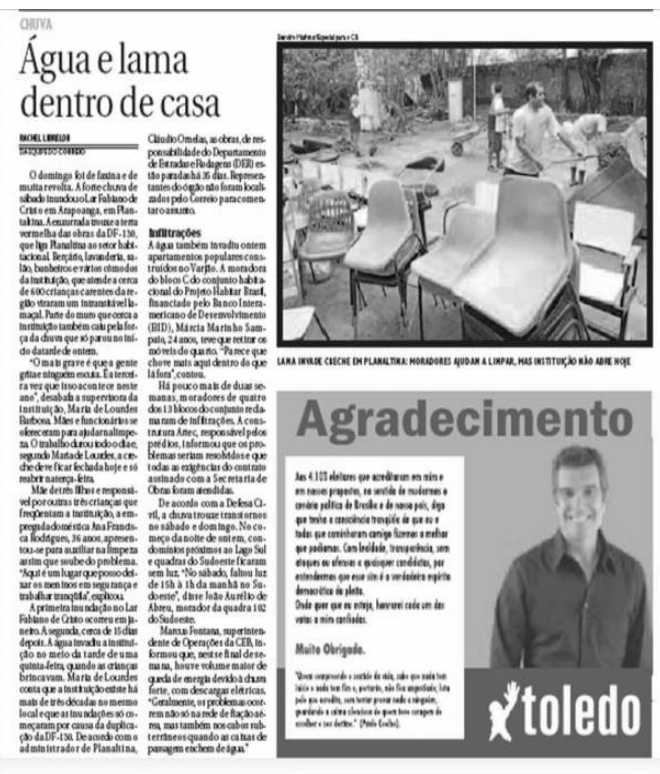

Figura 5. Repercussão na imprensa do evento chuvoso do dia 07 de outubro de 2006.

Fonte: http://www.correioweb.com.br/

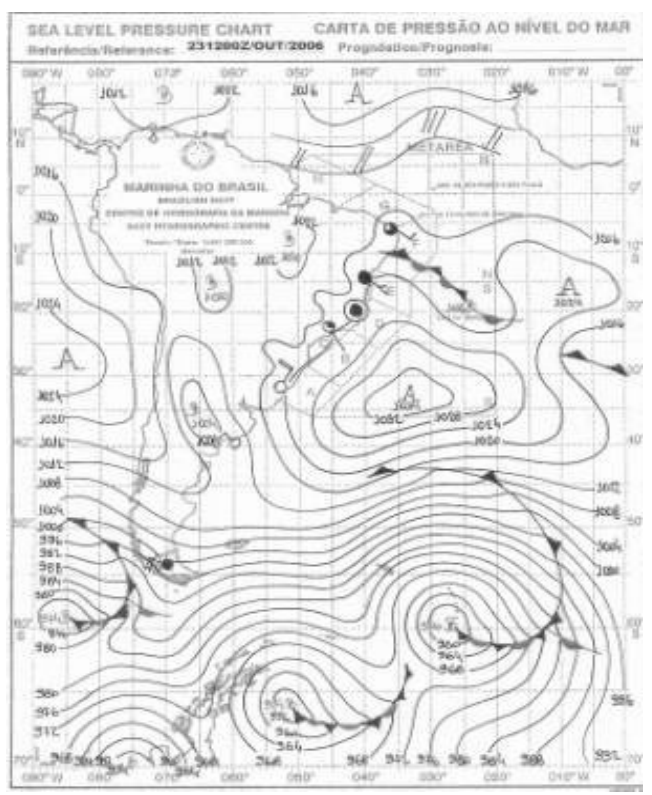

Figura 6. Carta sinótica do dia 23 de outubro às 12:00 UTC.

Fonte:http://www.mar.mil.br/dhn/chm/mete o/prev/cartas/cartas.htm

Contudo, o pior evento ocorreu entre o fim da tarde do dia 26 e a madrugada do dia 27 . O INMET registrou $103,1 \mathrm{~mm}$ de chuva que foi provocada por áreas de instabilidade associadas a uma frente fria proveniente do sul do país. Com esse evento, a estação Brasília (INMET) bateu o recorde de volume de chuva acumulado para o mês de outubro. Do início do mês até o dia 27, o acumulado estava em $513,6 \mathrm{~mm}$, superando os $425,8 \mathrm{~mm}$ de outubro de 1981 , o recorde anterior.

No Plano Piloto dois prédios comerciais ficaram alagados, várias tesourinhas - nome regional dado aos viadutos que ligam as quadras 200 às 100 das asas sul e norte do Plano Piloto - foram interditadas devido aos alagamentos. Porém, a Vila Fercal, assentamento urbano localizado na parte oeste do Distrito Federal e uma região que apresenta relevo bastante acidentado, foi a mais atingida, sendo considerada, neste trabalho, a área de maior risco de inundação. A Defesa Civil contabilizou 177 famílias desalojadas na vila em virtude da chuva forte. A imprensa noticiou os impactos causados pela chuva com o título: "Temporal acaba em destruição". (figura 8). De fato, a região oeste do Distrito Federal, segundo Steinke e Steinke (2001), após um estudo realizado com dados de precipitação de um período de mais de 20 anos, concluíram que a região oeste do Distrito Federal constitui-se naquela onde há maior ocorrência de chuvas. Corrobora com os autores, Barros (2003), após a análise do regime de chuvas que ocorre na região. 


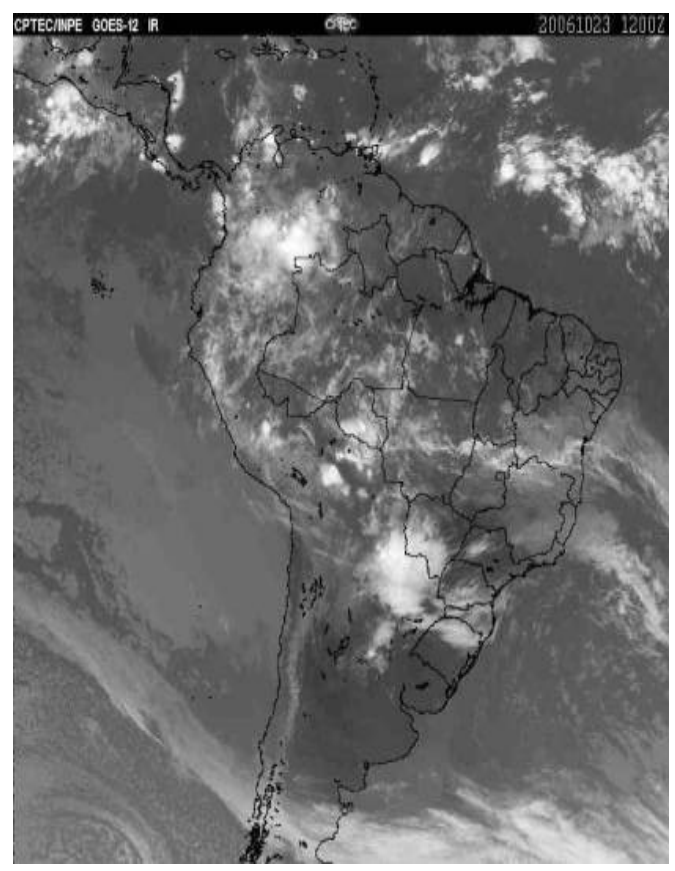

Figura 7. Imagem do satélite GOES 12, canal infra-vermelho do dia $23 / 10$ às 12:00 UTC.

Fonte: $h t t p: / / s a t e l i t e . c p t e c . i n p e . b r /$

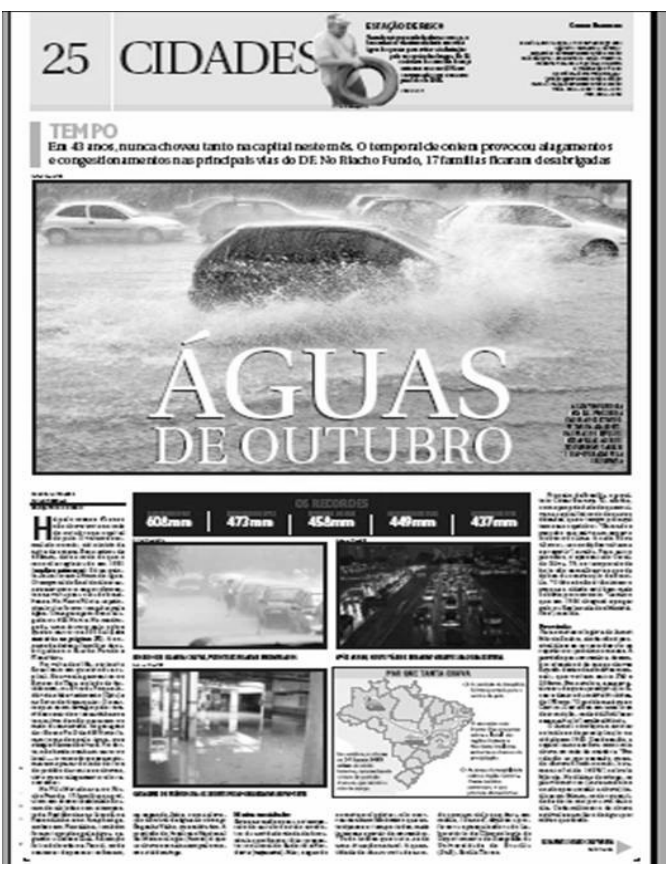

Figura 8. Repercussão na imprensa do excesso de chuva no mês de outubro.

Fonte: $h t t p: / / w w w . c o r r e i o w e b . c o m . b r$

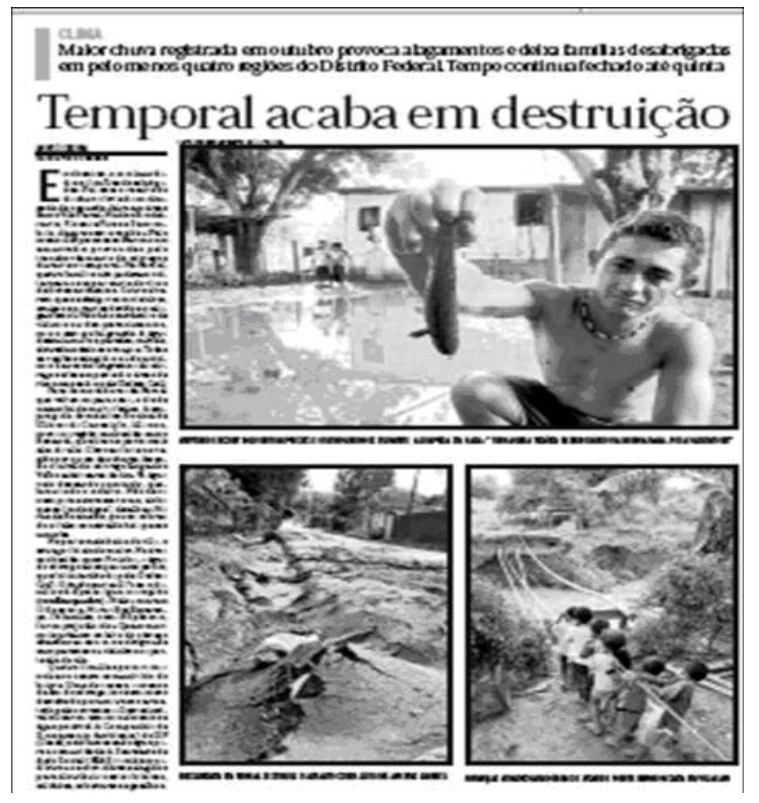

Figura 9. Repercussão na imprensa sobre os problemas gerados pelo maior evento de chuva do mês de outubro, no dia 27.

Fonte: http://www.correioweb.com.br 


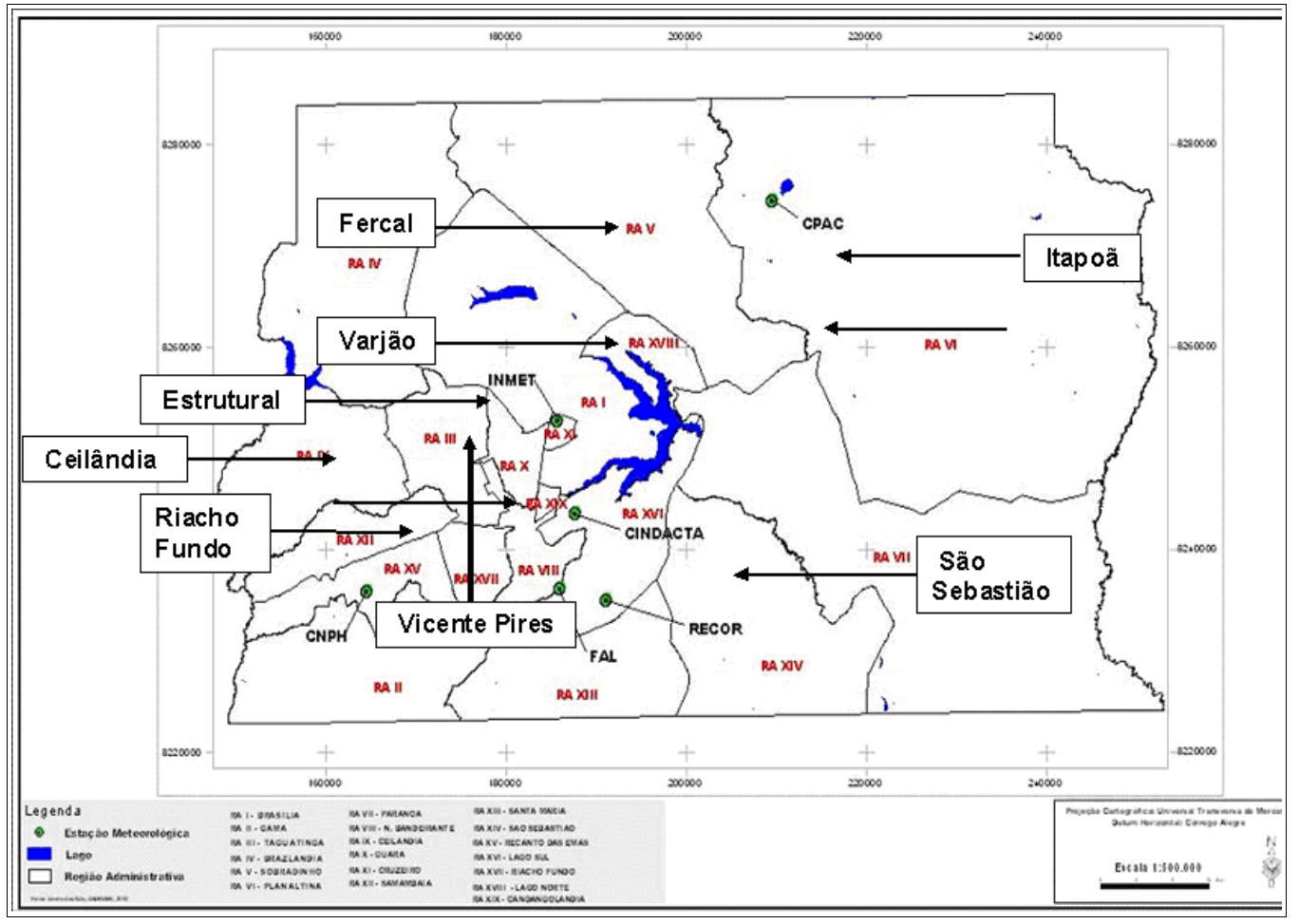

Figura 10. Principais áreas de risco de inundação no Distrito Federal.

\section{Considerações finais}

Quando se fala em desastre climático, o primeiro pensamento das pessoas está relacionado com eventos de grande magnitude tais como, tornados, furações e etc. Isso ocorre porque, no senso comum, são esses os eventos que geram problemas, perdas e mortes. Porém, tempestades tropicais, como as que ocorrem na região Centro-Oeste e no Distrito Federal também geram impactos negativos e, dependendo da área atingida, até mortes. Sendo assim, é possível afirmar que a população do Distrito Federal também sofre com desastres de origem climática e, a cada ano que passa, as ocorrências tendem a aumentar em função da ocupação em áreas de risco.

Foi o que ocorreu em outubro de 2006. Há 43 anos não era registrada tanta chuva no mês de outubro no Distrito Federal. Entre as razões para os temporais observados e que causaram inúmeros desastres na região está a convergência de umidade entre o sul da Amazônia e os sistemas frontais presentes nas regiões Sudeste e Centro-Oeste que provocaram a formação de áreas de instabilidade. Vale ressaltar que não se pode delegar somente à chuva a origem dos desastres registrados durante o mês. O fato de a população ocupar áreas de risco, como as margens dos córregos, a desorganização urbana da capital e a impermeabilização crescente do solo que gera aumento no escoamento superfici- 
al também contribuem para a geração dos desastres identificados durante e após eventos intensos de chuva. Resta ao poder público tomar conhecimento das informações sobre o clima, eventos climáticos extremos e os riscos a desastres naturais no Distrito Federal para aprimorar a prevenção junto à comunidade.

\section{Referências bibliográficas}

ALEXANDER, D.E. Natural hazard on na unquiet earth. In: MATHEUS, J. A. \& HERBERT, D.T. Unifying Geography. London: Routledge-Taylor and Francis Group, 2004. p. 266-268.

BARROS, J.R. A chuva no Distrito Federal: o regime e as excepcionalidades do ritmo. Rio Claro, 2003. 221 f. Dissertação (mestrado) - Instituto de Geociências e Ciências Exatas, Departamento de Geografia, Universidade Estadual Paulista.

BRANDÃO, A.M. de P.M. O clima urbano da cidade do Rio de Janeiro. São Paulo, 1996. 362 f. Tese (Doutorado). Departamento de Geografia. Universidade de São Paulo.

Climanálise - Boletim de Monitoramento e Análise Climática Aspectos climáticos e sinóticos no Brasil, Outubro de 2006. Disponível em: <http://www.cptec.inpe.br/products/climanalise> Acesso em 12 de fev. 2007.

DEPARTAMENTO NACIONAL DE METEOROLOGIA. Normais Climatológicas (1961 1990). Brasília: DNMET, 1992.

MONTEIRO, C.A. de F. A Frente Polar Atlântica e as Chuvas de Inverno na Fachada Sul-(Oriental do Brasil contribuição metodológica à análise rítmica dos tipos de tempo no Brasil). Série Teses e Monografias, 1 IGEOG/ USP, São Paulo, 1969. 69p.

NIMER, E. Climatologia do Brasil. Rio de Janeiro: IBGE, 1989 (série recursos Naturais e Meio Ambiente).

STEINKE, V.A. e STEINKE, E.T. (2001). Variação espaço-temporal da pluviosidade no Distrito Federal e seus condicionantes. In: Simpósio Brasileiro de Climatologia Geográfica, 4, 2001, Rio de Janeiro. Anais... Rio de Janeiro: UFRJ. 1 CD ROM.

STEINKE, E.T. Considerações sobre variabilidade e mudança climática no Distrito Federal, suas repercussões nos recursos hídricos e informação ao grande público. Brasília, 2004. 201 p. Tese (Doutorado em Ecologia) Instituto de Ciências Biológicas, Departamento de Ecologia, Universidade de Brasília.

ZAVATINI, J.A. A Climatologia Geográfica Brasileira, o enfoque dinâmico e a noção de ritmo climático - desenvolvimento, progresso e perspectivas. Boletim Climatológico, Presidente Prudente, v. 1, n. 2, p. 11-20, 1996.

ZAVATTINI, J.A. A produção brasileira em climatologia: o tempo e o espaço nos estudos do ritmo climático. Terra Livre, São Paulo, v. 1, n. 20, p. 65-99, 2003. 